\title{
Internal Glow Discharge-Fourier Transform Ion Cyclotron Resonance Mass Spectrometry
}

\author{
K. L. Goodner, K. E. Milgram, C. H. Watson, and J. R. Eyler \\ Department of Chemistry, University of Florida, Gainesville, Florida \\ C. Dejsupa \\ Department of Chemistry and Biochemistry, Brigham Young University, Provo, Utah \\ C. M. Barshick \\ Chemical and Analytical Sciences Division, Oak Ridge National Laboratory, Oak Ridge, Tennessee
}

\begin{abstract}
A glow discharge (GD) ion source has been developed to work within the high magnetic field of a Fourier transform ion cyclotron resonance (FTICR) mass spectrometer. Characterization of this source revealed that the optimum operating voltage, pressure, and current are significantly lower than those for normal glow discharges. The sputter rate was lowered to $1 / 30$ th of that found with a normal glow discharge source operated external to the high magnetic field region. Operation of the GD source closer to the FTICR analyzer cell than with previous experimental designs resulted in improved ion transport efficiency. Preliminary results from this internal GD source have established detection limits in the low parts per million range for selected elemental species. (J Am Soc Mass Spectrom 1996, 7, 923-929)
\end{abstract}

$\mathrm{I}$ on formation in Fourier transform ion cyclotron resonance mass spectrometry (FTICR/MS) has been extended in recent years to include virtually every type of ion source that has been used with other types of mass analyzers. These sources include electron impact (EI), chemical ionization (CI), matrix-assisted laser desorption (MALDI) [1], and electrospray ionization (ESI) [2], as well as many less common ionization sources. For example, sources such as ${ }^{252} \mathrm{Cf}$ ionization [3], laser microprobe ionization [4], fast-atom bombardment (FAB) [5] and continuous flow FAB [6], and secondary ion mass spectrometry (SIMS) [7] have been demonstrated. Many of these ionization sources operate at relatively high pressures, which are incompatible with those required by the high resolution Fourier transform ion cyclotron resonance (FTICR) detection scheme. Thus, the problem of transporting ions formed at relatively high pressure to the FTICR analyzer cell located at the center of a high field magnet (often superconducting) must be solved. This issue has been resolved in one of two ways: (1) formation of the ions outside the magnetic field and subsequent transport to the cell (over distances of 1-2 m depending on the magnet's field strength and geometry) or (2) formation of the ions inside the high magnetic field (either directly inside or several centimeters away from the cell).

Several methods have been used to transport ions from outside the magnetic field through the fringing

Address reprint requests to Dr. J. R. Eyler, P.O. Box 117200, Gainesville, FL 32611-7200.

fields of the magnet to the analyzer cell. McIver $[8,9]$ and co-workers employed an rf-only mode quadrupole ion guide to transport ions from an external source through the fringing magnet field to the FTICR analyzer cell. Another approach for external injection was the use of an electrostatic "wire" ion guide, where the potential difference between a rigid wire and a surrounding cylinder creates a potential well that directs ions to the trapped ion analyzer cell [10]. An alternative approach accelerates the ions through the fringing fields by using a set of electrostatic lenses, followed by deceleration prior to entering the cell [11]. Of particular relevance to the work reported here are the transfer optics previously designed in our laboratory for external injection of ions created in a glow discharge probe-source $[12,13]$. These transfer optics involved three acceleration-focusing lenses directly following the exit orifice of the glow discharge (GD) chamber, which allowed ions to pass through a conductancelimiting orifice in a small metal plate whose potential could be varied. Ions were then transferred $\sim 1 \mathrm{~m}$ through a flight tube whose potential also could be adjusted, then passed through an ion decelerator assembly directly before the analyzer cell so that the ions could be slowed and trapped in the ICR cell.

External formation of ions with subsequent transport to the FTICR analyzer cell greatly facilitates access to the ion source for repairs, exchange with other ion sources, adjustments, and modifications. In addition, the external injection method makes it easier to employ several stages of differential pumping to obtain 
the desired FTICR cell operating pressures of less than $1 \times 10^{-8}$ torr $\left(1.33 \times 10^{-6} \mathrm{~Pa}\right)$. However, the additional intricacy of the transfer optics adds dramatically to the expense, complexity, and time required for signal optimization. A potential drawback with external injection is ion loss during transport, which can adversely affect limits of detection and lead to decreased sensitivity.

Many limitations to external injection can be overcome by formation of ions in or adjacent to the analyzer region, within the high magnetic field necessary for FTICR mass detection. This type of formation is simplified if the normal ion source operates with pressures in the $1 \times 10^{-8}$ torr $\left(1.33 \times 10^{-6} \mathrm{~Pa}\right)$ range (such as a laser desorption source), but is much more complicated if the ion source operates at higher pressures [e.g., 1 torr (133 Pa) for GD sources or atmospheric pressure for ESI sources]. One method that has been devised uses a source pumping arrangement that consists of a series of concentric tubes that enclose the ion source [14]. Exit orifices located at the tube ends serve as conductance limits for the pumping, which allows a pressure drop from atmospheric to the $10^{-8}$-torr $\left(10^{-6}\right.$. $\mathrm{Pa}$ ) range in a distance of only $25 \mathrm{~cm}$. Placement of the source within the high magnetic field eliminates the need for complicated transport and focusing optics, because ions that exit the source at large angles are focused by the magnetic field into relatively small cyclotron orbits and tend to form a beam of low divergence. Because ion formation takes place much closer to the cell than with external sources, ion transport efficiencies are higher and problems associated with ion transfer from external sources are reduced. However, the internal source approach also has disadvantages. Location of the source within the high magnetic field region makes repairs, exchange with other ion sources, adjustments, and modifications more difficult and time-consuming.

For use with the GD technique, we have built a concentric tube vacuum chamber similar to that described by Laude and co-workers [14-16] for electrospray ionization. The diameters of the concentric tubes were optimized for maximum conductance of the differentially pumped regions within the constraints of a $15.2-\mathrm{cm}-(6-i n .-)$ o.d. vacuum chamber and a $1.91-\mathrm{cm}-$ $\left(\frac{3}{4}\right.$-in.-) o.d. probe.

Glow discharge ion sources coupled with FTICR/MS have received only limited interest to date $[12,13,17-20]$. The advantage of GD-FTICR/MS is the high mass resolution, which virtually eliminates problems due to interferences often observed in other forms of GD mass spectrometry $[17,19]$. The possibility of performing rf glow discharge experiments within the magnetic field of a FTICR/MS was alluded to, but not demonstrated, in a paper by Shohet et al. [21]. Marcus et al. [17] reported an external rf glow discharge coupled with FTICR/MS, where externally produced ions simply were allowed to drift into the analyzer cell. Barshick and Eyler [12, 13] developed a dc glow dis- charge source that used a set of electrostatic lenses to transport ions to the cell; this approach exhibited detection limits of $15 \mathrm{ppm}$ for ${ }^{60} \mathrm{Ni}$ [13]. Other work by Watson et al. [18] showed lower limits of detection, but involved the use of more complicated external ion injection instrumentation.

The effect of relatively low magnetic fields on glow discharges has been studied previously [22-25]. These fields, of no more than $800 \mathrm{G}$, were shown to increase ion currents in a GD-quadrupole mass spectrometer [22]. The suggested enhancement mechanism was that the magnetic field increases the electron path length, which thus increases the formation of both argon metastables and analyte ions. Other effects attributed to the presence of a magnetic field were higher sputter rates, higher currents at given voltages, and lower operating pressures $[22,23]$.

By using the concentric tube vacuum chamber approach, we successfully operated a glow discharge probe-source inside a high magnetic field region $(\sim 1.5 \mathrm{~T})$ of the FTICR superconducting magnet and we obtained detection limits similar to those previously reported from our laboratory [13] with external source operation. This article reports our initial investigations of sputtering rates, optimization of operating parameters, and determination of limits of detection (LOD) for the high magnetic field glow discharge probe-source.

\section{Experimental}

A laboratory-built FTICR mass spectrometer (Figure 1) was modified with a concentric tube differential pumping arrangement (Figure 2) that provided three stages of differential pumping to lower pressure from 1 torr $(133 \mathrm{~Pa})$ in the glow discharge probe-source to $5 \times 10^{-8}$ torr $\left(6.5 \times 10^{-6} \mathrm{~Pa}\right)$ in the FTICR analyzer

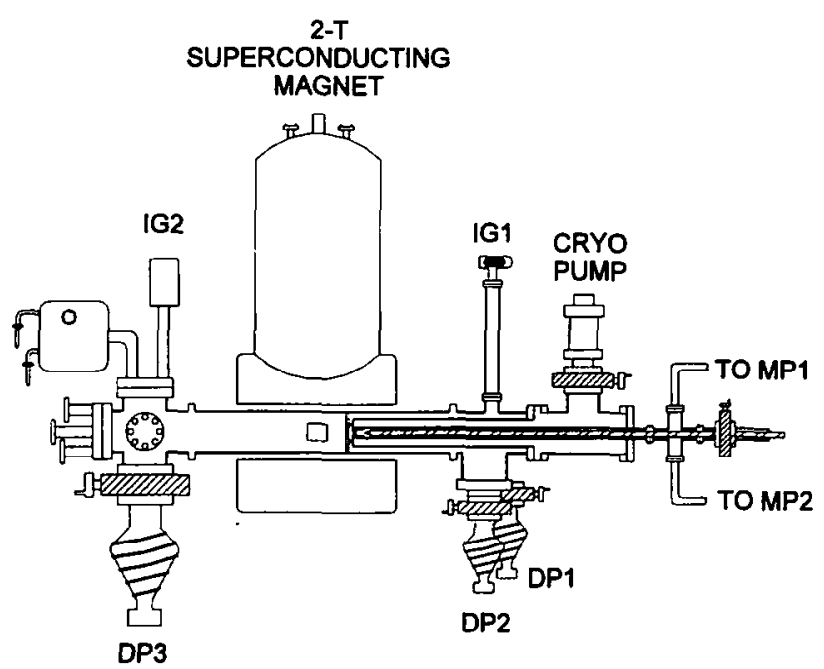

Figure 1. Schematic representation of the FTICR mass spectrometer that includes locations of analyzer cell, conductance limits, and internal glow discharge probe-source. (IG = ionization gauge; $\mathrm{DP}=$ diffusion pump; $\mathrm{MP}=$ mechanical pump.) 


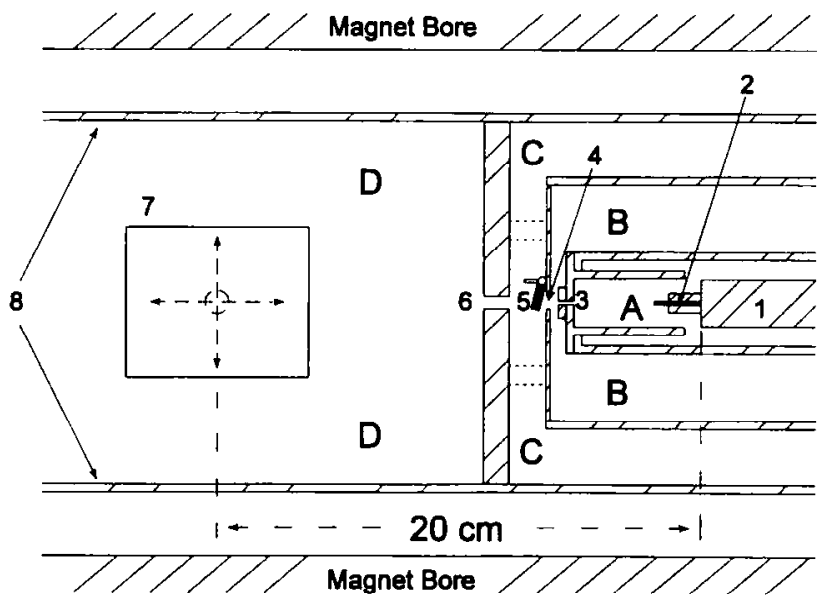

Figure 2. Concentric tube arrangement with different pressure regimes indicated. The diagram is drawn to scale except for the conductance limits, which are exaggerated for clarity. Region A is pumped by two $500-\mathrm{L} / \mathrm{min}$ mechanical pumps. Region $B$ is pumped by an $800-\mathrm{L} / \mathrm{s}$ cryopump. Region $\mathrm{C}$ is pumped by two $300-\mathrm{L} / \mathrm{s}$ diffusion pumps. Region $\mathrm{D}$ is pumped by a $700-\mathrm{L} / \mathrm{s}$ diffusion pump. $1,1.91-\mathrm{cm}\left(\frac{3}{4}-\mathrm{in}\right.$.) stainless steel sample probe; 2 , glow discharge sample pin; 3 , removable conductance limit and Delrin holder; 4 , second conductance limit; 5, electromagnetic shutter; 6 , third conductance limit; 7, ICR cell; $8,15.2-\mathrm{cm}$ (6-in.) outer vacuum chamber.

cell. As shown in Figure 2, there are four distinct pressure regions, labeled $A-D$. Region $A$ is the region of the glow discharge and is maintained at approximately 1 torr (133 Pa) of argon. Regions $\mathrm{A}$ and $\mathrm{B}$ are separated by a $0.5-\mathrm{mm}$-diameter conductance limit. An $800-\mathrm{L} / \mathrm{s}\left(\mathrm{N}_{2}\right)$ cryopump maintains pressure in the latter region at value of $1-5 \times 10^{-5}$ torr (1.3-6.5 $\times$ $10^{-3} \mathrm{~Pa}$ ). A magnetic shutter was employed on the conductance plate that separates regions $B$ and $C$. This shutter was opened to allow neutrals and ions to pass through a 4-mm orifice during ion accumulation and then closed to facilitate better differential pumping. In region $\mathrm{C}$ two $300-\mathrm{L} / \mathrm{s}$ oil diffusion pumps maintained pressures of $5 \times 10^{-6}$ (shutter open) and $4 \times 10^{-7}$ (shutter closed) torr $\left(6.5 \times 10^{-4} \mathrm{~Pa}\right.$ and $5 \times 10^{-5} \mathrm{~Pa}$, respectively). A second 4-mm conductance limit separated regions $C$ and $D$, and a $700-\mathrm{L} / \mathrm{s}$ oil diffusion pump was used to pump the latter (analyzer cell) region. Pressures of $6 \times 10^{-7}$ (shutter open) and $5 \times$ $10^{-8}$ (shutter closed) torr $\left(8 \times 10^{-5} \mathrm{~Pa}\right.$ and $6.5 \times$ $10^{-6} \mathrm{~Pa}$, respectively) were achieved.

The 1.91-cm- $\left(\frac{3}{4}-\right.$ in. -$)$ o.d. GD probe design is shown in Figure 3. A high voltage feedthrough (Part FTT1213251, Kurt J. Lesker Co., Clairton, PA) with a hollow conductor was modified by welding to it a threaded stainless steel sleeve. This allowed the source assembly to be screwed into the (threaded) probe to simplify disassembly for maintenance and alterations. The sample holder in Figure 3 (labeled G) also was threaded so that sample holders could be accessed easily and changed to accommodate pin cathodes, hollow cathodes, or planar cathodes. A $\frac{1}{4}-\frac{1}{8}$-in. copper adapter (labeled D in Figure 3) was brazed onto the

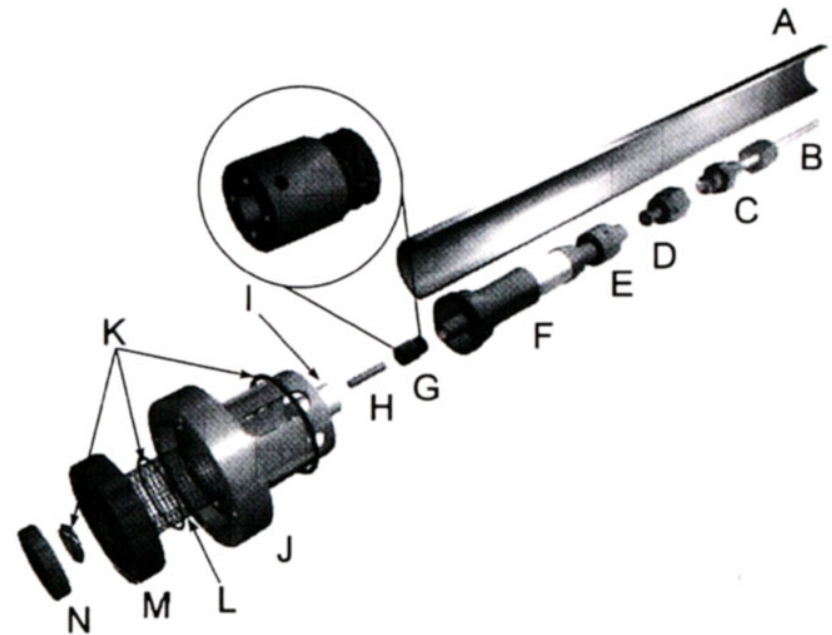

Figure 3. Glow discharge source-probe. A, 1.91-cm- ( $\frac{3}{4}$-in.-) o.d. stainless steel probe; $\mathrm{B}$, polyethylene argon delivery tube; C, 1/8-in. Swagelok union; D, $\frac{1}{8}-\frac{1}{4}$-in. adapter; E, high voltage connector; $F$, electrical feedthrough; $G$, sample pin holder; $\mathrm{H}$, sample pin; I, ceramic insulator; J, Delrin ${ }^{\text {Q }}$ holder; $\mathrm{K}$, Viton ${ }^{8}$ O-rings; $L$, stainless steel wire mesh; $M$, stainless steel conductance limit holder; $N$, stainless steel removable conductance limit.

end of the high voltage feedthrough opposite the sample holder; this permitted connection of a $\frac{1}{8}$-in.-o.d. gas supply line. A protective ceramic cover (I in Figure 3) was placed over the sample to confine the glow discharge to the tip of the sample, which protruded through the cover.

For the FTICR-GD mass spectrometry experiments a superconducting 2-T prototype magnet (originally purchased from Nicolet FTMS) was used. Data were collected via an IonSpec data station (IonSpec, Irvine, CA). Fifty time-domain broadband transients each of $128 \mathrm{~K}$ data points were acquired and averaged. The data were multiplied by a Hamming apodization function [26] and zero filled once prior to Fourier transformation. Industrial grade argon (99.998\% pure; Bitec, Inc., Tampa, FL) was used as the discharge gas as well as the bath gas for experiments that involved quadrupolar axialization [27], which utilized a laboratory-built switching box. The metal samples were small cylinders ( $\sim 2-\mathrm{mm}$ diameter by $20 \mathrm{~mm}$ long) with about a 5-8-mm length of the sample exposed when it was mounted in the sample holder and covered by the ceramic cap (both shown in Figure 3). A National Institute of Standards and Technology (NIST) Standard Reference Material (SRM) 1261a steel sample was used for determining LODs.

\section{Results and Discussion}

Figure 4 shows two spectra of an NIST SRM 1261a stainless steel sample obtained with (1) the external GD probe-source [12] and (2) the internal GD probesource that is the subject of this article. The spectrum obtained with external injection (Figure 4a) shows a 

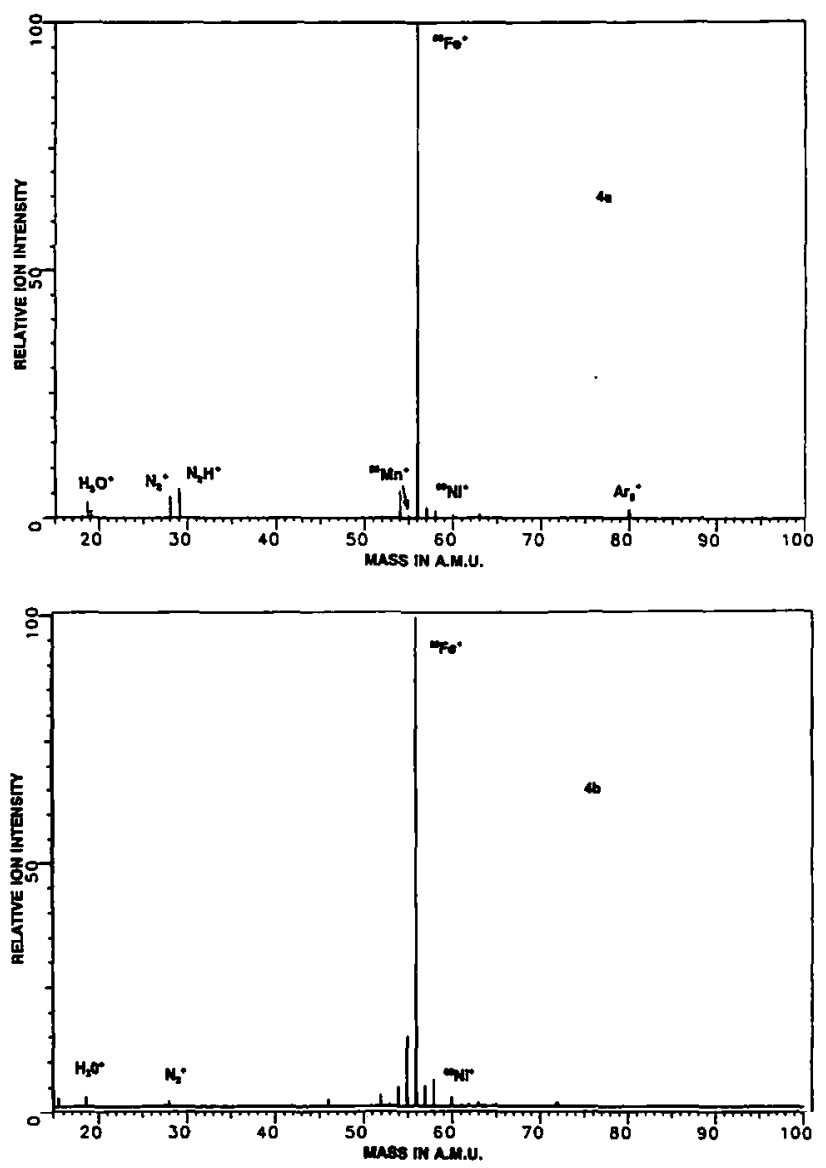

Figure 4. Mass spectra of NIST SRM 1261a steel sample obtained by using (a) an external source [12] and (b) the internal probe-source. (Figure $4 \mathrm{a}$ is reprinted by permission of the publisher from Barshick and Eyler, J. Am. Soc. Mass Spectrom. 1992, 3, 122-127. Copyright 1992 by Elsevier Science Inc.)

base peak of ${ }^{56} \mathrm{Fe}^{+}\left({ }^{40} \mathrm{Ar}^{+}\right.$was ejected before data collection) and several minor species. The spectrum obtained with internal ion formation (Figure $4 \mathrm{~b}$ ) shows similar peaks and has approximately the same signalto-noise ratio. Several minor peaks in both spectra are due to $\mathrm{H}_{2} \mathrm{O}^{+}, \mathrm{N}_{2}^{+}, \mathrm{O}_{2}^{+}$, and ${ }^{60} \mathrm{Ni}^{+}$. A peak from ${ }^{56} \mathrm{Fe}^{16} \mathrm{O}^{+}(m / z 72)$ is not present in the external source spectrum, but is seen for the internal probe-source, whereas the argon dimer ${ }^{40} \mathrm{Ar}_{2}^{+}$, is seen only in the external source spectrum. It is unclear if these differences can be attributed to more than the typical variations observed in conventional GD mass spectrometry that result from gas load, purity, and so forth. Similarly, no definitive explanation can be given for the enhanced ${ }^{55} \mathrm{Mn}^{+}$and ${ }^{60} \mathrm{Ni}^{+}$signals produced by the internal probe-source, although they may result from more thermal emission if the glow discharge in that source has a somewhat higher temperature than the external source.

\section{Magnetic Field}

An important consideration for characterization of the glow discharge that operates within a high magnetic field is the effect of the field on the discharge process. To gain insight into this effect, the relationship between magnetic field and glow discharge power supply voltage needed to maintain a constant discharge current was examined. This examination was accomplished by measurement of the power supply voltage as the probe-source was inserted progressively into the concentric tube assembly at various pressures. Figure 5 shows the results of these measurements. The data on magnetic field strength as a function of distance from the cell (left ordinate and abscissa of Figure 5) were reported previously by Barshick and Eyler [13].

As the probe-source was advanced progressively further into the vacuum chamber, moving toward higher magnetic field, the power supply voltage needed to maintain a constant discharge current of $0.9 \mathrm{~mA}$ was observed to decrease (become less negative). From $\sim 100$ to $60 \mathrm{~cm}$ from the center of the magnet, the required voltage decreased. This decrease is consistent with results reported by Bentz and Harrison [23] that showed that as an external magnetic field was increased from 200 to $500 \mathrm{G}$ the current for a constant voltage discharge increased. In our experiment with a constant current discharge, the voltage decreased with increasing magnetic field, as can be seen in Figure 5.

Metal probe guides located at 58 and $38 \mathrm{~cm}$ caused a perturbation of discharge operating conditions as the probe passed these points. The increase in voltage that began at $\sim 30 \mathrm{~cm}$, however, did not coincide with the presence of a guide, but did occur simultaneously with a rapid increase in the magnetic field strength. This increase in discharge voltage required for constant current is attributed to the induced cyclotron motion of the positively charged argon ions in the magnetic field, which would necessitate a higher voltage (more negative). Two possible explanations are proposed for this observation. First, argon ions that undergo cyclotron motion in the magnetic field at some distance from the sample pin will spiral down toward the sample under influence of the applied voltage. With constant voltage, the force of impact from these spiral-

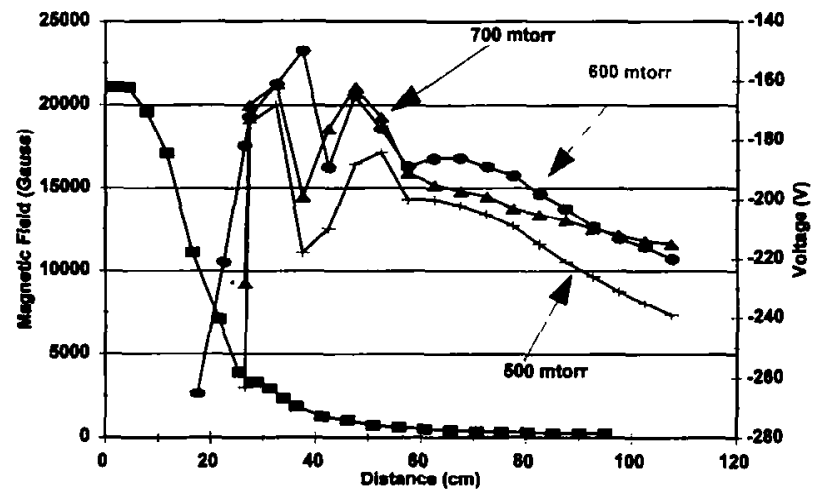

Figure 5. Power supply voltage necessary to maintain constant discharge current of $0.9 \mathrm{~mA}$ as a function of magnetic field strength at different pressures. 
ing ions will be less than that of argon ions attracted directly to the sample in the absence of a magnetic field. Therefore, a higher voltage is needed to produce the same impact force of argon ions on the sample. Another possibility is that the cyclotron motion of the argon ions increases the path length that the ions must traverse before impact with the sample. This increased path length leads to a greater number of collisions, which would lower the kinetic energy of the argon ions and therefore lessen their force of impact on the sample. Higher potentials also would be needed to overcome this effect.

\section{Pressure, Voltage, and Current Studies}

Because the sample holder and discharge chamber used for these studies were different from those used by Barshick and Eyler [12, 13], it was decided to investigate the operating characteristics of the new design. We found that the operating pressure, voltage, and current of the internal glow discharge probesource were of the same order of magnitude as had been observed in external GD sources [28, 29]; however, the internal discharge does operate at lower pressures, voltages, and currents than the external. The discharge was found to have an onset voltage of about $-330 \mathrm{~V} ;-400 \mathrm{~V}$ was the upper limit for stable operation at 750 mtorr $(100 \mathrm{~Pa})$.

It was observed that as the source pressure increased (at constant - 375-V discharge potential), the ion signal also increased to a maximum at $850 \mathrm{mtorr}$ $(113 \mathrm{~Pa})$ and then decreased. This pattern is consistent with other studies [30, 31]; the explanation given by Hess et al. [30, 31] for this phenomenon is that the metal ion signal follows the population of the metastable argon ( $\left.\mathrm{Ar}^{*}\right)$. It has been shown that as the pressure increases at constant discharge potential, there is an increase in the argon metastable $\left(\mathrm{Ar}^{*}\right)$ population; above a local maximum collisional processes dominate, which results in a decrease in $\mathrm{Ar}^{*}$ and $\mathrm{M}^{+}$ [30].

The studies reported here show that the probesource operates similarly to a conventional GD source external to a magnetic field, but with optimal operating conditions around $0.9 \mathrm{~mA},-375 \mathrm{~V}$, and $850 \mathrm{mtorr}$ (113 Pa).

\section{Sputter Rate}

By using a solid iron pin, a sputter rate of $0.25 \mathrm{mg} / \mathrm{h}$ $(n=3, \sigma=0.087)$ was determined in the high magnetic field source by sputtering the sample for $2 \mathrm{~h}$ and measuring the mass difference before and after sputtering. Under similar conditions (voltage, current, and pressure), but outside the magnetic field, a $0.23-\mathrm{mg} / \mathrm{h}$ sputter rate $(n=6, \sigma=0.098)$ was observed. By performing a two sample $t$-test [32] on the sputter rate data, it was determined that the two means have a greater than $95 \%$ chance of having the same true mean. This determination supports our belief that the lower voltage, pressure, and current needed for optimal operation of the high magnetic field GD probesource are not dictated by the magnetic field, but instead result from probe design. This sputter rate is approximately $1 / 30$ th that found in conventional GD sources [33] and in our earlier [12, 13] external injection method. Thus, the amount of sample needed for analysis is reduced by over an order of magnitude in the probe-source designed for high magnetic field operation. A lower sputter rate would be expected to produce fewer ions, which results in lower signals. However, signal levels comparable to external ionization were achieved. Improved ion transport in the internal design compensates for the reduced sputter rate and more of the ions formed in the discharge eventually are detected in the FTICR analyzer cell. Because the signal levels for both internal and external source operation were comparable, the internal method offers no great advantage unless the sample size is limited, where the lower sputter rate of this design would be desirable. If an ample amount sample is available, the external method is more convenient.

\section{Limits of Detection}

To evaluate limits of detection (LOD) for the high magnetic field design, a comparison was made to the LOD obtained by Barshick and Eyler [13] on a GDFTICR system of the same magnetic field, but with external injection of the analyte ions. Both investigations used the ${ }^{60} \mathrm{Ni}^{+}$peak from NIST SRM 1261a. The same method of determination of the limit of detection was used in each study: take the inverse of the sensitivity (intensity per parts per million) and multiply it by three times the standard deviation of the mean of the background. The lowest LOD reported for external injection was $15 \mathrm{ppm}$ [13]. To reproduce the previous work as closely as possible, a pulsed valve was utilized. The gas from the pulsed valve and the ion decelerator used in the external source studies serve the same purpose-to lower the kinetic energy of the ions to facilitate trapping. With the decelerator configuration that Barshick and Eyler used, a 15-ppm detection limit of ${ }^{60} \mathrm{Ni}$ was achieved. In comparison, an 11-ppm detection limit for the same species was seen in this work (Table 1). Because the limits of detection were essentially the same for the external and internal injection methods and only $1 / 30$ th the sample was used with the internal probe-source (due to lower sputter rates, vide supra), a 30-fold improvement in ion transport was observed. If we assume $7.5-\mathrm{mg} / \mathrm{h}$ sputter rate for the external method, a 1-min acquisition time for 50 scans, and a LOD of $15 \mathrm{ppm}$, an absolute detection limit of $1.9 \mathrm{ng}$ is determined. If we assume a $0.25-\mathrm{mg} / \mathrm{h}$ sputter rate for the internal method, a 1-min acquisition time for 50 scans, and a LOD of $6 \mathrm{ppm}$ (the best achieved for the internal probe-source design), an absolute detection limit of 
Table 1. Limits of detection (LOD) of ${ }^{60} \mathrm{Ni}$ for various experimental conditions

\begin{tabular}{lc}
\hline Conditions $^{\mathrm{a}}$ & LOD (ppm) \\
\hline \hline No ejection & 38 \\
${ }^{56} \mathrm{Fe}^{+}$ejected & 28 \\
No ejection. Pulse valve on; QA off & 11 \\
No ejection. Pulse valve on; QA on & 8 \\
Eject $m / z$ 55 -57. Pulse valve on; QA on & 6 \\
External injection [13] & 15 \\
\hline
\end{tabular}

QA denotes quadrupolar axialization.

$25 \mathrm{pg}$ is determined, which is a substantial increase over the external injection method and is comparable to other forms of GD mass spectrometry.

\section{FTICR Advantages}

There are several additional techniques in FTICR/MS that can be applied to obtain lower detection limits. These include ion ejection [34], use of pulsed valves for thermalization [35], and quadrupolar axialization [27]. Each method was investigated in conjunction with use of the internal GD probe-source.

The FTICR cell can contain an upper limit of approximately one million ions before excessive spacecharge effects distort the observed spectrum. Application of rf energy at a specific cyclotron frequency gives ions enough energy to eject them from the cell [34]. With the ejection of ions in the mass range 55-57 $u$, the relative number of nickel to iron ions increased, which resulted in a lower detection limit for nickel. For example, the LOD for ${ }^{60} \mathrm{Ni}$ improved from $38 \mathrm{ppm}$ to $28 \mathrm{ppm}$ when ${ }^{56} \mathrm{Fe}$ was ejected from the cell (Table 1).

Quadrupolar axialization (QA) is a method in which an rf waveform is applied differentially to two sets of opposing cell plates [27]. The energy imparted during the axialization process, with the help of a bath gas, collapses the ions back to the center of the cell which allows for larger cyclotron radii to be obtained during excitation and for remeasurement of ion packets. A laboratory-built switching box currently under evaluation was used for quadrupolar axialization. In this experiment we observed only a $27 \%$ improvement in LOD (from 11 to $8 \mathrm{ppm}$ ) when QA was used to axialize ${ }^{60} \mathrm{Ni}^{+}$ion. We attribute such a relatively minor improvement to the fact that quadrupolar axialization realizes its greatest improvement with a pulsed ion source, because more signal can be obtained per pulse. Our source was not pulsed and we feel that incorporation of a pulsed GD source will lower LODs significantly.

Last, we combined the three techniques (ejection of ${ }^{56} \mathrm{Fe}^{+}$, use of pulsed gas, and employment of our prototype quadrupolar axialization switching box) and obtained a LOD of $6 \mathrm{ppm}$, which is a $60 \%$ improvement over the result of external injection experiments. This result leads to detection limits of $\sim 25 \mathrm{pg}$ for the internal glow discharge probe-source when sputtering rate and scan time are taken into account, compared with $\sim 1900 \mathrm{pg}$ for the external source.

\section{Conclusions}

Glow discharge sources do work when they are located inside the FTICR magnetic field and the probe-source design presented here has the added benefit of a lower sputtering rate, which enhances LODs. The relative proximity of the source to the FTICR cell results in higher ion transport efficiency compared to previous external injection methods [12, 13]. The 30-fold improvement in ion transport seen in this work gives limits of detection comparable to external injection (low parts per million), but with significantly lower sample consumption, which leads to a limit of detection of $25 \mathrm{pg}$ for ${ }^{60} \mathrm{Ni}$. Finally, it has been shown that the behavior of a glow discharge with this probe-source design in a magnetic field of approximately $1.5 \mathrm{~T}$ is comparable to that when no magnetic field is present.

\section{Acknowledgments}

Research was sponsored in part by the Office of Naval Research and in part by the U.S. Department of Energy, Office of Basic Energy Sciences. Oak Ridge National Laboratory is managed for the DOE by Lockheed Martin Energy Systems, Inc., under contract DE-ACO5-84OR21400.

\section{References}

1. Hettich, R. L.; Buchanan, M. V. J. Am. Soc. Mass Spectrom. 1991, 2, 22-28.

2. Henry, K. D.; Williams, E. R.; Wang, B. H.; McLafferty, F. W.; Shabanowitz, J.; Hunt, D. F. Proc. Natl. Acad. Sci. U.S.A. 1989, 86, 9075-9078.

3. Tabet, J. C.; Rapin, J.; Poretti, M.; Gaumann, T. Chimia 1986, $40,169-171$

4. Brenna, J. T.; Creasy, W. R.; McBain, W.; Soria, C. Rev. Sci. Instrum. 1988, 59, 873-879.

5. Laukien, F. H.; Allemann, M.; Bischofberger, P.; Grossmann, P.; Kellerhals, Hp.; Kofel, P. ACS Symp. Ser. 1987, 359, 81-99.

6. Watson, C. H.; Kruppa, G. H.; Wronka, J.; Laukien, F. H. Rapid Commun. Mass Spectrom. 1991, 5, 249.

7. Castro, M. E.; Russell, D. H. Anal. Chem. 1985, 57, 2290-2293.

8. McIver, R. T., Jr. Int. J. Mass Spectrom. Ion Processes 1990, 98, 35-50.

9. Mclver, R. T., Jr. Anal. Chem. 1990, 62, 878-880.

10. Limbach, P. A.; Marshall, A. G.; Wang, M. Int. J. Mass Spectrom. Ion Processes 1993, 125, 135-143.

11. Kofel, P.; Alleman, M.; Kellerhals Hp.; Wanczek, K.-P. Int. J. Mass Spectrom. Ion Processes 1985, 65, 97.

12. Barshick, C. M.; Eyler, J. R. J. Am. Soc. Mass Spectrom. 1992, 3, 122-127.

13. Barshick, C. M.; Eyler, J. R. J. Am. Soc. Mass Spectrom. 1993, 4, 387-392.

14. Hofstadler, S. A.; Laude, D. A., Jr. J. Am. Soc. Mass Spectrom. $1992,3,615-623$.

15. Hofstadler, S. A.; Schmidt, E.; Quan, Z.; Laude, D. A., Jr. J. Am. Soc. Mass Spectrom. 1993, 4, 68-76. 
16. Guan, Z.; Campbell, V. L.; Drader, J. J.; Hendrickson, C. L.; Laude, D. A., Jr. Rev. Sci. Instrum. 1995, 66, 4507-4515.

17. Marcus, R. K.; Cable, P. R.; Duckworth, D. C.; Buchanan, M. V.; Pochkowski, J. M.; Weller, R. R. Applied Spectrosc. 1992, 46, 1327-1330.

18. Watson, C. H.; Wronka, J.; Laukien, F. H.; Barshick, C. M.; Eyler, J. R. Spectrochim. Acta, Part B 1993, 48, 1445-1448.

19. Watson, C. H.; Wronka, J.; Laukien, F. H.; Barshick, C. M.; Eyler, J. R. Anal. Chem. 1993, 65, 2801.

20. Watson, C. H.; Wronka, J.; Laukien, F. H.; Barshick, C. M.; Eyler, J. R. Anal. Chem. 1996, 68, 573-575.

21. Shohet, J. L.; Phillips, W. L.; Lefkow, A. R. T.; Taylor, J. W.; Bonham, C.; Brenna, J. T. Plasma Chem. Plasma Processes 1989, 9, 207-215.

22. Bentz, B. L. Ph.D. Dissertation, University of Virginia, 1979.

23. Bentz, B. L.; Harrison, W. W. Anal. Chem. 1982, 54, 1644-1646.

24. McCaig, L.; Sesi, N.; Sacks, R. Appl. Spectrosc. 1990, 44, 1176-1182.

25. Brewer, S.; Holbrook, T.; Shi, Z.; Trivedi, K.; Sacks, R. Appl. Spectrosc. 1991, 45, 1327-1332.
26. Aarstol, M.; Comisarow, M. B. Int. J. Mass Spectrom. Ion . Processes 1987, 76, 287-297.

27. Schweikhard, L.; Guan, S.; Marshall, A. G. Int. I. Mass Spectrom. Ion Processes 1992, 120, 71-83.

28. Bentz, B. L.; Harrison, W. W. Prog. Anal. Spectrosc. 1988, 11, 53.

29. King, F. L.; Harrison, W. W. Mass Spectrom. Rev. 1990, 9 , 285-317.

30. Hess, K. R.; Harrison, W. W. Anal. Chem. 1988, 60, 691-696.

31. Smith, R. L.; Serxner, D.; Hess, K. R. Anal. Chem. 1989, 61, 1103-1108.

32. Massart, D. L.; Vandeginste, B. G. M.; Deming, S. N.; Michotte, Y.; Kaufman, L. Chemometrics: A Textbook. Elsevier: Amsterdam, 1990; pp 42-43.

33. Barshick, C. M. Ph.D. Dissertation, University of Virginia, 1990.

34. Comisarow, M. B.; Grassi, V.; Parisod, G. Chem. Phys. Lett. 1978, 57, 413.

35. Carlin, T. J.; Freiser, B. S. Anal. Chem. 1983, 55, 571-574. 